\title{
Measuring and Comparing the Value-at-Risk Using GARCH and CARR Models for CSI 300 Index
}

\author{
Chunchou Wu \\ Department of Business Management, Xiamen Huaxia University, Xiamen, China \\ Email: wucc@hxxy.edu.cn, wuccl23@seed.net.tw
}

How to cite this paper: $\mathrm{Wu}$, C.C. (2018) Measuring and Comparing the Value-atRisk Using GARCH and CARR Models for CSI 300 Index. Theoretical Economics Letters, 8, 1179-1187. https://doi.org/10.4236/tel.2018.86078

Received: January 22, 2018

Accepted: April 20, 2018

Published: April 23, 2018

Copyright $\odot 2018$ by author and Scientific Research Publishing Inc. This work is licensed under the Creative Commons Attribution International License (CC BY 4.0).

http://creativecommons.org/licenses/by/4.0/

\section{(c) (i) Open Access}

\begin{abstract}
This article is the first to provide a detailed method for range-based CARR model to estimate the VaR and its out-of-sample prediction. In this paper, we use GARCH and CARR volatility models to compare the VaR's out-of-sample forecasting performance. Using the historical simulation method as benchmark for VaR estimation, we found that the historical simulation approach for $\mathrm{VaR}$ measurement is more conservative than GARCH and CARR methods. The mean violation rate for the CARR VaRs is lower than that of the GARCH VaRs. Meanwhile, the CARR VaR is able to deliver lower required capital levels without producing bigger violations. This paper argued that the CARR $\mathrm{VaR}$ valuation approach is suitable as an internal model method for financial institution in $\mathrm{VaR}$ forecasting.
\end{abstract}

\section{Keywords}

VaR, CARR, GARCH, Volatility Forecasting

\section{Introduction}

There is no consistent approach for forecasting market risk. Value-at-Risk (VaR) has become a standard benchmark for measuring financial risk. The formula for determining the market risk capital was set by 1996 Market Risk Amendment to the 1988 Basel I Accords. An international financial institution experiencing an excess number of violations based on their required VaR will be penalized by having to set aside a larger amount of risk capital. The VaR models are able to be broadly defined as a quantitative tool whose goal is to assess the possible loss that can be incurred by an international financial institution over a given time period and for a given portfolio of assets. A common, though not very good, 
assumption is that the change in the asset value over the time horizon is normally distributed. The mean change in the asset value is usually assumed to be zero. Also see Hull [1]. Based on these assumptions, the concept for measuring $\mathrm{VaR}$ can be simplified as $\mathrm{VaR}$ is equal to $\sigma N^{-1}(X)$, where $X$ is the confidence level, $\sigma$ is the volatility of the asset's value change over the time horizon, and $N^{-1}$ is the inverse cumulative normal distribution. Namely, regardless of the time period, the measurement of $\mathrm{VaR}$ for a specific confidence level is proportional to the volatility of asset's value change.

The volatility of portfolio return is time-varying and predictable, but forecasting the future level of volatility is not easily. One of the main reasons is the volatility forecasts are sensitive to the specification of the volatility model. Conventionally, the returned based GARCH family models are popularized for describing volatility process. Surveying from a bundle of related literatures, the GARCH family models have provided effective tools in estimating the volatility process. Also see Engle [2]. The GARCH models can express the most important stylized features of asset return volatility, for instance, the phenomenon of clustering for return series and lognormality.

Giot and Laurent [3] assess the performance of the RiskMetrics, skewed Student APARCH and skewed Student ARCH models for their application in VaR estimation. ${ }^{1}$ They proposed that the skewed Student APARCH model performs best in all six commodity markets. Giot and Laurent [4] compare the performance of a daily ARCH type model with the performance of a model based on the daily realized volatility when the one-day-ahead $\mathrm{VaR}$ is to be computed. They implied the VaR based on skewed Student distribution model for the realized volatility provides adequate one-day-ahead VaR forecasts for two stock indexes and two exchange rate returns. Jorion [5] found that VaR-based volatility forecasts based on banks' publicly available VaR disclosures are significantly related to future market risk. Jorion [5] suggests that investors can compare the risk profiles of financial institutions by their disclosed VaR. Berkowitz and O'Brien [6] indicated that the bank internal VaR models are not better than standard GARCH model. The GARCH model of profit and loss provides for lower VaRs and is better at predicting changes in volatility. Namely, the GARCH model permits comparable risk scale with less regulatory capital.

The range variable is much more efficient volatility proxy, a fact known since the paper of Parkinson [7]. Afterwards, Alizadeh, Brandt and Diebold [8] proposed that the distribution of the log range conditional on volatility is approximately Gaussian, making range based volatility models highly effective and easily to estimate the parameters of volatility models. Brandt and Jones [9] using daily S\&P 500 index data and established the range based EGARCH models for volatility forecasting. Lin, Chen and Gerlach [10] using range data with the idea of smooth transition structure to forecast volatility process. They documented substantial gains in estimation efficiency from using range data instead of return data. The literature on range based volatility models includes Garman and Klass ${ }^{1}$ Ding et al. [2] proposed the asymmetric power ARCH (APARCH) model. 
[11], Gallant, Hsu and Tauchen [12], Yang and Zhang [13] and Chou [14], Asai and Brugal [15] among others. Chiang and Wang [16] proposed range volatility can measure the contagion effect for volatility. Specifically, Molnar [17] pointed out the well-properties of consistence for range-based volatility estimators.

Above all, Chou [14] proposed conditional autoregressive volatility model that involve the range variable, namely, the so-called CARR model. The CARR model can capture the dynamics of conditional mean of the range. Engle, Gallo and Velucchi [18] studied the volatility spillover in East Asian financial markets using the MEM-based Approach. To estimate the coefficients of CARR model also have to incorporate the MEM-based approach. In other words, the range based volatility can serve as a powerful substitution for the return based volatility model in describing the volatility process.

In this paper, we aim to address the $\mathrm{VaR}$ topic by comparing the performance of a return-based daily GARCH model with the performance of a CARR model based on the daily range volatility model when the one-day-ahead VaR measure is to be calculated. Chen, Gerlach, Hwang and McAleer [19] use range-based quantile regression to predict the VaR. However, they did not compare the performance for different volatility approaches. This task is accomplished by the data for the CSI 300 stock index and the CSI 300 index futures. The CSI 300 index is a value weighted stock market index comprising 300 large capitalization traded A-share stocks. ${ }^{2}$ The CSI 300 index covers more than $90 \%$ of the total market value in Chinese stock markets. All the data in this paper are collected from the dataset of Bloomberg. For a better asset allocation, it is essential to realize the $\mathrm{VaR}$ measurements for China financial markets with various volatility models for investors. The VaR modeling is an intuitive application of volatility models as $\mathrm{VaR}$ measures are directly related to the expected volatility over the specific time horizon given some confidence level.

The rest of this paper is organized as follows. Section 2 reviews the GARCH and CARR models for estimating volatility process and its application for VaR measurement. Section 3 describes the data and empirical results. Finally, the conclusion is organized in Section 4.

\section{VaR Estimation with GARCH and CARR Model}

An important feature of GARCH model is the asset value's conditional variance $h_{t}$ which is determined by model parameters and recent return observations. Let daily return for asset is $r_{t}$ at time $t$. The simple $\operatorname{GARCH}(1,1)$ model can be expressed as Equation (1):

$$
\begin{gathered}
r_{t}=\varepsilon_{t} \\
\varepsilon_{t} \mid I_{t-1} \sim N\left(0, h_{t}\right) \\
h_{t}=\alpha_{0}+\alpha_{1} \varepsilon_{t-1}^{2}+\beta_{1} h_{t-1}
\end{gathered}
$$

${ }^{2}$ The CSI 300 index is the first equity index jointly launched by the Shenzhen Stock Exchange and Shanghai Stock Exchange. 
where $\alpha_{0}, \alpha_{1}$ and $\beta_{1}$ are parameters to be estimated. $I_{t-1}$ denotes the available information set until time $t-1$. The GARCH parameters can be estimated with data available up to time $t$.

Basically, the 99 percent $V a R$ prediction at time $t$ is given by

$$
\operatorname{VaR}_{t+1} \mid I_{t}=r_{t+1}-2.33 \sqrt{\sigma_{t+1}^{2}}
$$

The symbol of $r_{t+1}$ denotes asset's return at time $t+1$. The symbol of $\sigma_{t+1}^{2}$ denotes the conditional variance of the asset.

We collect the daily data of CSI 300 index spot and futures series from 24 May 2010 to 16 December 2016. There are 1597 daily data for this empirical study. To obtain stable estimates for the initial period, estimates for days 1 through 1,000 are in-sample to construct the GARCH model. ${ }^{3}$ While comparing the performance for $V a R$ prediction based on the GARCH model, we introduced the historical simulation (HS, hereafter) for $V a R$ estimation with the 1000 sample size as the criticalvalue. Days when the actual loss exceeds $V a R$ are referred to as exceptions or violations. If exceptions happen on about $1 \%$ of the days, we can feel reasonably comfortable with the GARCH model for computing $V a R$. Rolling out-of-sample forecasts begin after day 1000. Out-of-sample estimates are updated daily. Given parameter estimates, we get the next day's 99 percent VaR assuming normality of the model's disturbance term.

Based on $\operatorname{GARCH}(1,1)$ model, we can take the expectation value for the conditional variance equation for one-step-ahead. Hence,

$$
\begin{gathered}
h_{t+1}=\alpha_{0}+\alpha_{1} \varepsilon_{t}^{2}+\beta_{1} h_{t} \\
E_{t}\left(h_{t+1}\right)=E\left(\alpha_{0}+\alpha_{1} \varepsilon_{t}^{2}+\beta_{1} h_{t}\right)=\alpha_{0}+\left(\alpha_{1}+\beta_{1}\right) \sigma^{2}+\alpha_{1}\left(\varepsilon_{t}^{2}-\sigma^{2}\right)+\beta_{1}\left(h_{t}-\sigma^{2}\right) \\
=\sigma^{2}+\alpha_{1}\left(\varepsilon_{t}^{2}-\sigma^{2}\right)+\beta_{1}\left(h_{t}-\sigma^{2}\right)=\hat{h}_{t+1}
\end{gathered}
$$

Here the $E_{t}\left(h_{t+1}\right)$ indicates the conditional variance on time $t+1$ given information set on time $t . \sigma^{2}$ is the unconditional variance for this GARCH model. The unconditional variance can be regarded as the long term average variance for this series. Meanwhile, it represents that the GARCH prediction can be thought of as a weighted average of unconditional variance. It is easily to obtain the unconditional variance $\left(\sigma^{2}\right)$ by taking expectation from the variance equation of GARCH model, namely $E_{t}\left(h_{t}\right)=E_{t}\left(\alpha_{0}+\alpha_{1} \varepsilon_{(t-1)}^{2}+\beta_{1} h_{t-1}\right)$. In other words, $\sigma^{2}=\alpha_{0}+\alpha_{1} \sigma^{2}+\beta_{1} \sigma^{2}$. So, the unconditional variance is given by $\sigma^{2}=\alpha_{0} / 1-\alpha_{1}-\beta_{1}$.

The GARCH parameters are estimated with the 1000 daily data. To get stable estimates for the initial period, forecasts for 1 through 1000 are in-sample. Next the GARCH parameter estimated are fitted from the sample 2 through 1001. Rolling out-of-sample forecasts begin after day 1000. One-day-ahead estimate is updated daily. We collect $596 \mathrm{VaR}$ estimates from the GARCH-VaR approach. Then, comparing to the 99 percent VaR benchmark value which is inferred by ${ }^{3} \mathrm{VaR}$ is denoted in monetary units. We opted for $\$ 10,000$ as our initial value of the CSI-300 stock indexand futures portfolio respectively. 
historical simulation method based on the same in sample period. Finally, we are able to compare the targeted violation rate to the predicted violation rate.

The range based models are also suitable to delineate the process of asset's volatility. The related studies indicated that range variable has relative efficient in describing volatility process, but did not many empirical support. Chou [14] pointed out the poor empirical performance is due to the inappropriate dynamic model fitting. Chou [14] proposes the CARR model that use range variables to capture the process of volatility. The asset's range can be defined as the difference between the highest and lowest prices in a logarithm type over a fixed time period. The CARR model can be constructed as:

$$
\begin{gathered}
R_{t}=\lambda_{t} \mu_{t} \\
\mu_{t} \mid I_{t-1} \sim \exp (1 ; .) \\
\lambda_{t}=\omega+\alpha R_{t-1}+\beta \lambda_{t-1} .
\end{gathered}
$$

The variable $R_{t}$ is the difference between $\ln \left(H_{t}\right)$ and $\ln \left(L_{t}\right)$, and $H_{t}$ and $L_{t}$ are the highest and lowest intraday price in a trading day respectively. The variable $\lambda_{t}$ is the conditional mean of the range during the trading day $t$. The symbol $\mu_{t}$ is the innovation assumed to follow the exponential distribution with a unit mean. Finally, the $\omega, \alpha$ and $\beta$ are parameters to be estimated. Similar to the out-of-sample prediction for GARCH model, we can obtain the one-step-ahead prediction that is derived from CARR model.

$$
\hat{\lambda}_{t+1}=\left(E \lambda_{t+1} \mid I_{t}\right)=\hat{\omega}+\hat{\alpha} R_{t}+\hat{\beta} \lambda_{t}
$$

The same sample size is used to estimate the coefficients of CARR model. Following the Equation (5), it is easily to get the one-day-ahead volatility prediction. Again, the CARR parameter estimates are obtained from the sample 2 through 1001. Similar to the GARCH model, the 596 range-based volatility estimates for the one-day-ahead prediction could be obtained from the CARR model.

Due to the range-based volatility scale for CARR model is different from the return-based scale for GARCH model. For the comparative purpose in VaR estimation with these two volatility models, the range volatility indicators from CARR model has to be adjusted.

$$
\hat{h}_{t}=\psi \hat{\lambda}_{t}+e_{t}, \quad t=1001,1002, \cdots, 1597
$$

where $\hat{h}_{t}$ is conditional variance estimate from the GARCH model and $e_{t}$ is the residual term. Let the adjusted forecasted volatility from CARR model at time $t$ is $A F V_{t}$. We can transfer the range volatility indicator as $A F V_{t}$ series in Equation (7) which have the same scale with return-based GARCH model.

$$
A F V_{t}=\hat{\varphi} \hat{\lambda}_{t}
$$

Thus, we can use the concept of Equation (2) to express the one-day-ahead out-of-sample VaR forecast for CARR model. ${ }^{4}$

${ }^{4} \mathrm{Chou}, \mathrm{Wu}$ and Liu [20] in dealing with ranged-based DCC model use similar approach. 


\section{Data and Empirical Analysis}

We collect the daily observations of CSI-300 stock index and its futures index from 24 May 2010 to 16 December 2016. ${ }^{5}$ There are 1597 daily data for our VaR study. All the data are collected from Bloomberg.

The coefficient estimates of GARCH and CARR models for in-sample data, namely, day 1 to day 1000 are demonstrated in Table 1 . All of these coefficient estimates satisfy the requirement of econometrics. For instance, these coefficients are positive and are significant different from zero from $\mathrm{t}$ values. $\hat{\alpha}_{1}+\hat{\beta}_{1}$ is equal to 0.947 and 0.923 for CSI-300 spot and futures respectively. It symbols the spot and futures index return series are stationary and will not have the phenomenon of divergence. Meanwhile, judging from Q statistics, there is no autocorrelation for residual series after GARCH/CARR model fitting. Table 1 offers credible evidence about the GARCH and CARR models in volatility estimation for CSI-300 index.

The mean value of VaR represents the average for all of the one-day-ahead out-of-sample VaR forecasting based on the historical simulation method, GARCH model and CARR model and displays their results in column 3, 4 and 7 respectively. The number of out-of-sample size is 597. In Table 2, regardless of the CSI-300 spot or futures index, the mean value of VaRs that derived by historical simulation approach are greater in absolute value than the mean value of VaRs for the method of GARCH and CARR models. It represents that the historical simulation approach for VaR measurement is more conservative than GARCH and CARR methods. Besides, Ross [21] pointed out the futures trading transmits more information than its spot market. Thus, it is reasonable to obtain the oscillation is more volatile for the CSI- 300 futures market than the CSI-300 spot market. The one-day-ahead VaR expected values are bigger in absolute value for CSI-300 futures than its corresponding CSI-300 spot index.

The historical simulation approach for $\mathrm{VaR}$ measurement is appropriate as a benchmark in analyzing the VaR violation rate for GARCH and CARR models. Judging from the column 5 and 8 in Table 2, the number of violation for GARCH and CARR are near the $99 \%$ confidence level. Apparently, the time series VaRs measurements achieve the targeted violation rate. Both of the GARCH and CARR models are appropriate to perform the VaR valuation. Particularly, the mean violation rate for the CARR VaRs is lower than that of the GARCH VaRs. These empirical results indicate a potentially outstanding advantage for the CARR model. The magnitudes of the VaR forecasts are used to determine regulatory capital requirements for financial institutions, and likely influence institution's internal capital allocations as well. The CARR VaR is able to deliver lower required capital levels without producing bigger violations. This reflects the CARR volatility model VaR's greater responsiveness to change in the volatility of the CSI-300 spot and futures index.

${ }^{5}$ The day of 24 May 2010 is the first trading day after last futures delivery day. The delivery day for current futures is the third Friday of the month. 
Table 1. Estimation of GARCH and CARR model using CSI-300 spot and futures.

\begin{tabular}{|c|c|c|c|c|c|c|c|c|c|c|}
\hline & \multicolumn{5}{|c|}{ GARCH } & \multicolumn{5}{|c|}{ CARR } \\
\hline & \multicolumn{5}{|c|}{$r_{t}=\varepsilon_{t}$} & \multicolumn{5}{|c|}{$R_{t}=\lambda_{t} \mu_{t}$} \\
\hline & \multicolumn{5}{|c|}{$\varepsilon_{t} \mid I_{t-1} \sim N\left(0, h_{t}\right)$} & \multicolumn{5}{|c|}{$\mu_{t} \mid I_{t-1} \sim \exp (1 ;)}$. \\
\hline & \multicolumn{5}{|c|}{$h_{t}=\alpha_{0}+\alpha_{1} \varepsilon_{t-1}^{2}+\beta_{1} h_{t-1}$} & \multicolumn{5}{|c|}{$\lambda_{t}=\omega+\alpha R_{t-1}+\beta \lambda_{t-1}}$. \\
\hline & $\hat{\alpha}_{0}$ & $\hat{\alpha}_{1}$ & $\hat{\beta}_{1}$ & $\mathrm{Q}(12)$ & LLF & $\hat{\omega}$ & $\hat{\alpha}$ & $\hat{\beta}$ & $\mathrm{Q}(12)$ & LLF \\
\hline Spot & $\begin{array}{c}1.063 \\
(1.987)\end{array}$ & $\begin{array}{c}0.133 \\
(3.765)\end{array}$ & $\begin{array}{c}0.814 \\
(15.537)\end{array}$ & $\begin{array}{l}21.319 \\
{[0.445]}\end{array}$ & -2293.301 & $\begin{array}{c}0.381 \\
(3.415)\end{array}$ & $\begin{array}{c}0.262 \\
(8.374)\end{array}$ & $\begin{array}{c}0.676 \\
(16.655)\end{array}$ & $\begin{array}{c}7.320 \\
{[0.831]}\end{array}$ & -1835.309 \\
\hline CSI-300 & $\hat{\alpha}_{0}$ & $\hat{\alpha}_{1}$ & $\hat{\beta}_{1}$ & $\mathrm{Q}(12)$ & LLF & $\hat{\omega}$ & $\hat{\alpha}$ & $\hat{\beta}$ & $\mathrm{Q}(12)$ & LLF \\
\hline Futures & $\begin{array}{c}1.021 \\
(2.432)\end{array}$ & $\begin{array}{c}0.211 \\
(4.153)\end{array}$ & $\begin{array}{c}0.712 \\
(16.021)\end{array}$ & $\begin{array}{l}23.551 \\
{[0.512]}\end{array}$ & -2107.547 & $\begin{array}{c}0.372 \\
(2.827)\end{array}$ & $\begin{array}{c}0.237 \\
(6.593)\end{array}$ & $\begin{array}{c}0.612 \\
(12.613)\end{array}$ & $\begin{array}{c}7.412 \\
{[0.845]}\end{array}$ & -1722.232 \\
\hline
\end{tabular}

Notes: 1) Sample period is from 24 May 2010 to 16 December 2016. All the daily data numbers are 1597. 2) Numbers in parentheses are $t$ values. Numbers in square bracket are p values. 3) All the original data are collected from Bloomberg.

Table 2. GARCH and CARR VaR prediction Comparisons, 24 May 2010 to 16 December 2016.

\begin{tabular}{cccccccccc}
\hline & \multicolumn{3}{c}{$\begin{array}{c}\text { Historical } \\
\text { Simulation }\end{array}$} & \multicolumn{3}{c}{ GARCH VaRs } & \multicolumn{3}{c}{ CARR VaRs } \\
\cline { 2 - 10 } & Obs. & Mean VaR & Mean VaR & $\begin{array}{c}\text { Number } \\
\text { Violation }\end{array}$ & $\begin{array}{c}\text { Mean } \\
\text { Violation }\end{array}$ & Mean VaR & $\begin{array}{c}\text { Number } \\
\text { Violation }\end{array}$ & $\begin{array}{c}\text { Mean } \\
\text { Violation }\end{array}$ \\
\hline CSI-300 Spot & 597 & -3.27 & -3.12 & 7 & -3.35 & -3.01 & 5 & -3.32 \\
CSI-300 Futures & 597 & -3.56 & -3.34 & 8 & -3.47 & -3.23 & 4 & -3.38
\end{tabular}

Notes: This table displays back testing of GARCH and CARR Value-at-Risk forecasts. All of the markettrading data are collected from Bloomberg. The GARCH VaR forecast is based on a simple GARCH $(1,1)$ with conditionally normal innovations and a CARR $(1,1)$ with conditionally exponent innovations. All of these mean VaRs are calculated by daily data.

Additionally, the number violation in Table 2 is to count the number of VaRs that hurdle the $99 \%$ criterion level. The mean violation is the average of VaRs conditional on those the VaRs estimates over the $99 \%$ criterion level. Evidently, the mean violation for CARR model is smaller than GARCH model in absolute value. Namely, using CARR VaR approach, financial institutions just have to prepare little capital to satisfy the requirement of regulation. From these empirical findings in Table 2, we realize an apparent fact that the VaR estimations are very sensitivity to volatility model selection. The range based volatility model is considerable to be a candidate for volatility process estimation and is workable in predicting out-of-sample VaR. After these empirical results, this paper argued that the CARR VaR measurement is suitable as an internal model method for financial institution in VaR forecasting.

\section{Conclusions}

This paper has presented the empirical study on the performance of GARCH and CARR VaR models for CSI-300 spot and futures index. The results show that the VaR out-of-sample prediction for the range-based CARR volatility model is better than the traditional return-based GARCH model. Historical simulation approach in VaR estimation appears more conservative phenomena that imply higher levels of capital coverage for trading risk. In other words, the predictive 
VaR by historical simulation approach is less useful as a measure of actual financial risk. Despite the insightful information employed by GARCH model, its $\mathrm{VaR}$ prediction did not outperform the CARR model for VaR estimation. Even though the time series models of range variable cannot account for position's sensitives to current risk shocks. But their flexibility and parsimony are precise and convenient for modelling the VaR information. The range-based CARR model may have advantages in forecasting and as an alternative method for identifying the shortcomings of other $\mathrm{VaR}$ valuation approaches.

\section{References}

[1] Hull, J. (2012) Risk Management and Financial Institution. 3rd Edition, John Wiely, Hoboken.

[2] Ding, Z., Granger, C.W.J. and Engle, R.F. (1993) A Long Memory Property of Stock Market Returns and a New Model. Journal of Empirical Finance, 1, 83-106. https://doi.org/10.1016/0927-5398(93)90006-D

[3] Giot, P. and Laurent, S. (2003) Market Risk in Commodity Markets: A VaR Approach. Energy Economics, 25, 435-457. https://doi.org/10.1016/S0140-9883(03)00052-5

[4] Giot, P. and Laurent, S. (2004) Modelling daily Value-at-Risk Using Realized Volatility and ARCH type Models. Journal of Empirical Finance, 11, 379-398. https://doi.org/10.1016/j.jempfin.2003.04.003

[5] Jorion, P. (2002) How Informative Are Value-at-Risk Disclosures? The Accounting Review, 77, 911-931. https://doi.org/10.2308/accr.2002.77.4.911

[6] Berkowitz, J. and O'Brien, J. (2002) How Accurate Are Value-at-Risk Models at Commercial Banks? Journal of Finance, 57, 1093-1111. https://doi.org/10.1111/1540-6261.00455

[7] Parkinson, M. (1980) The Extreme Value Method for Estimating the Variance of the Rate of Return. Journal of Business, 53, 61-65. https://doi.org/10.1086/296071

[8] Alizadeh, S., Brandt, M.W. and Diebold, F.X. (2002) Range-Based Estimation of Stochastic Volatility Models. Journal of Finance, 57, 1047-1091. https://doi.org/10.1111/1540-6261.00454

[9] Brandt, M.W. and Jones, C.S. (2006) Volatility Forecasting with Range-Based EGARCH Models. Journal of Business \& Economic Statistics, 24, 470-486. https://doi.org/10.1198/073500106000000206

[10] Lin, E.M.H., Chen, C.W.S. and Gerlach, R. (2012) Forecasting Volatility with Asymmetric Smooth Transition Dynamic Range Models. International Journal of Forecasting, 28, 384-399. https://doi.org/10.1016/j.ijforecast.2011.09.002

[11] Garman, M.B. and Klass, M.J. (1980) On the Estimation of Security Price Volatilities from Historical Data. Journal of Business, 53, 67-78. https://doi.org/10.1086/296072

[12] Gallant, A.R., Hsu, C.T. and Tauchen, G.E. (1999) Using Daily Range Data to Calibrate Volatility Diffusions and Extract the Forward Integrated Variance. Review of Economics and Statistics, 81, 617-631. https://doi.org/10.1162/003465399558481

[13] Yang, D. and Zhang, Q. (2000) Drift-Independent Volatility Estimation Based on High, Low, Open, and Close Prices. The Journal of Business, 73, 477-492. https://doi.org/10.1086/209650 
[14] Chou, R.Y. (2005) Forecasting Financial Volatilities with Extreme Values: The Conditional Autoregressive Range (CARR) Model. Journal of Money Credit and Banking, 37, 561-682. https://doi.org/10.1353/mcb.2005.0027

[15] Asai, M. and Brugal, I. (2012) Forecasting Volatility using Range Data: Analysis for Emerging Equity Markets in Latin America. Applied Financial Economics, 22, 461-470.

[16] Chiang, M.H. and Wang, L.M. (2011) Volatility Contagion: A Range Based Approach. Journal of Econometrics, 165, 175-189.

[17] Molnar, P. (2012) Properties of Range-Based Volatility Estimators. International Review of Financial Analysis, 23, 20-29.

[18] Engle, R., Gallo, G.M. and Velucchi, M. (2012) Volatility Spillover in East Asian Financial Markets: A MEM-Based Approach. Review of Economics and Statistics, 94, 222-223.

[19] Chen, C.W.S., Gerlach, R., Hwang, B.B.K. and McAleer, M. (2012) Forecasting Value-at-Risk using Nonlinear Regression Quantiles and the Intraday Range. International Journal of Forecasting, 28, 557-574.

[20] Chou, R.Y., Wu, C.C. and Liu, N. (2009) Forecasting Time-Varying Covariance with a Range-Based Dynamic Conditional Correlation Model. Review of Quantitative Financial Analysis, 33, 327-345. https://doi.org/10.1007/s11156-009-0113-3

[21] Ross, S.A. (1989) Information and Volatility: The No-Arbitrage Martingale Approach to Timing and Resolution Irrelevancy. Journal of Finance, 44, 1-17. 